\title{
Power-to-Gas: Analysis of potential decarbonization of Spanish electrical system in long-term prospective
}

\author{
Pilar Lisbona $^{a *}$, Guido Francesco Frate ${ }^{b}$, Manuel Bailera ${ }^{c}$, Umberto Desideri $^{\mathrm{b}}$

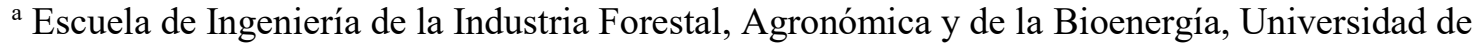 \\ Valladolid. Campus Universitario Duques de Soria, 42004, Soria, Spain. \\ ${ }^{\mathrm{b}}$ Department of Energy, Systems, Territory and Constructions. Università di Pisa. Largo Lucio \\ Lazzarino 1, polo A, 56122 Pisa, Italy. \\ ${ }^{\mathrm{c}}$ Escuela de Ingeniería y Arquitectura. Universidad de Zaragoza, Campus Río Ebro, María de \\ Luna 3, 50018, Zaragoza, Spain.
}

\begin{abstract}
Climate targets set by international organizations require the implementation of innovative technologies that ensure the decarbonization of energy sector. It may be partially achieved through a large penetration of Renewable Energy Sources. Massive energy storage is essential to handle excess electricity associated to RES and Power-to-Gas represents a promising option to chemically convert electricity surplus into energy carriers that may attend demands substituting fossil fuels. Aiming to avoid the influence of policies and market implications, this study approaches the decarbonization of Spanish system through the analysis of technical potential of RES. Several scenarios with different shares of RES are defined to cover a number of levels of energy demand. First, required wind and photovoltaic power has been estimated together with the required sizes of PtG to completely decarbonize electrical generation and industrial CHP. These scenarios may be reached by installing RES capacities below the technical potential coupled with PtG capacities between 80 and $90 \mathrm{GW}$. The stored energy amounts to $17 \%$ of total primary energy consumption. Secondly, scenarios are modified to consider denuclearization of electrical system. Required installed RES power still does not surpass the technical potential but become extremely high and the economic feasibility should be further analysed.
\end{abstract}

Keywords. Power-to-gas, Energy storage, Spanish scenario, Synthetic Natural Gas

\section{Introduction}

The current European energy policy was established in 2009 through the European Renewable Energy Directive (RED 2009/28/EC) [1], which sets a minimum of $20 \%$ of renewable share in the European final energy consumption by 2020 and a 10\% of renewable penetration in transport sector. The Commission updated these figures on November 2016 with a new proposal to ensure $27 \%$ renewables in the final energy consumption in the EU by 2030 [2].

\footnotetext{
${ }^{*}$ Corresponding author
} 
Each country should fulfill individual targets adapted to their different resources and the features of its own energy market. In the case of Spain, Spanish National Renewable Energy Action Plan (NREAP) gathered the 2011-2020 road map to meet the requirements of the Renewable Energy Directive. Spanish Royal Decree 661/2007 regulates electrical energy production under special regimes and provided for the drafting of a Renewable Energy Plan for implementation during the period 2011-2020 (REP 2011-2020) [3].

All Member States but the Netherlands showed an average 2013/2014 RES share equal or higher than their corresponding indicative trajectory of the European Directive. In 2015, European RES share was estimated to be around $16.4 \%$ of gross final energy consumption, while the Directive had projected only $13.8 \%$. Thus, Spain fulfilled its indicative European RED trajectory with a RES share of $16.2 \%$ in 2014 and $15.6 \%$ in 2015 [4]. However, larger penetration of renewables will be required in the next decades to achieve the global figure ( $20 \%$ in 2020 or $27 \%$ in 2030 ) and further work must be done to increase the current $0.5 \%$ of biofuels penetration in transport up to the Directive target [5].

The high shares of renewable sources in the electricity production system will lead to fluctuating periods of surplus power that could limit the operational predictability and flexibility of the electricity network [6] which will be only partially mitigated through Power to Heat and electrical vehicle deployment $[7,8]$. Thus, energy storage technologies are imperative in future electricity systems to manage renewable intermittent power. Current storage techniques (pumped hydroelectric storage, compressed air energy storage, flywheels, electrochemical storage, thermal energy storage) present limited storage potentials for large scale applications due special location requirements, short storage periods, slow discharge times or low energy storage densities [6]. Hydrogen energy storage (HES) overcomes these issues but it lacks a proper distribution infrastructure and transformation technology. Besides, HES implies additional handling safety measures. To avoid the mentioned limitations, Power-to-Gas energy storage has been pointed out in the last years as a very promising solution, which converts mixtures of renewable $\mathrm{H}_{2}$ and $\mathrm{CO}_{2}$ into synthetic natural gas (SNG) [9]. This final energy carrier can be easily stored and distributed through the existing gas grid and transformed into electricity or heat in conventional equipment with high efficiency, durability and limited investment costs (Figure 1) [10]. 


\section{Electricity network}

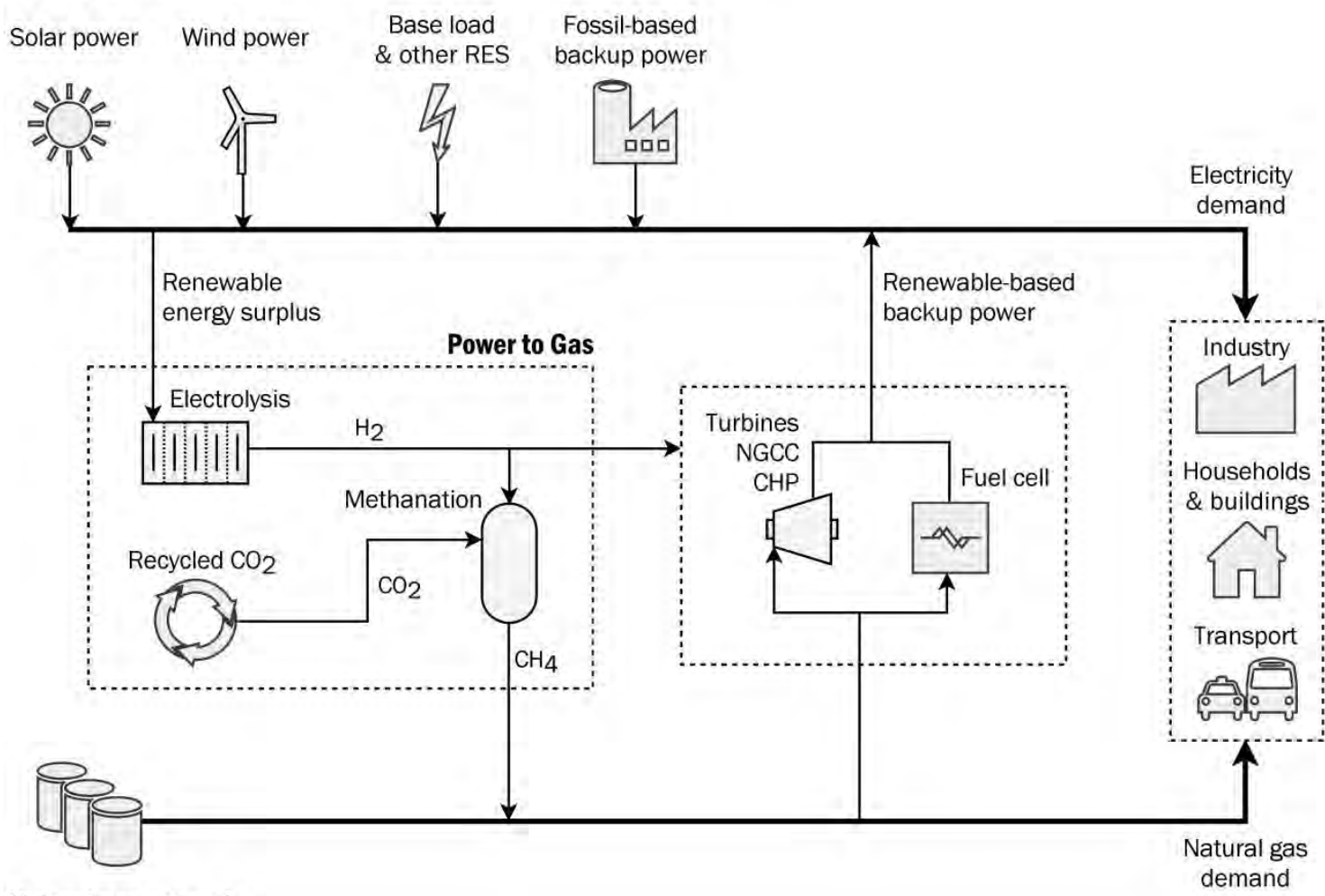

Natural gas network

Figure 1. Scheme of the energy system with $\mathrm{PtG}$

The potential increase of installed capacity of non-dispatchable energy sources in Spain is extremely high. Installed wind power in 2016 was $22.8 \mathrm{GW}$, while prospective studies established a feasible installed capacity of $52.5 \mathrm{GW}$ in 2030 [11] and a maximum potential in the country between 332-393 GW [12-14]. Similarly, photovoltaic installed capacity in 2016 was around 4.4 $\mathrm{GW}$, although several reports show there is room to install up to $66.5 \mathrm{GW}$ [15]. Moreover, several nuclear plants are near to finish their lifetime in Spain, so the nuclear debate is currently open. Both situations clearly foster the idea of a Spanish electrical system mostly based on renewable sources, thus promoting the decarbonization and the energetic independence. Emission factors of Spanish electricity producers ranges from 0 to $360 \mathrm{gCO}_{2} / \mathrm{kWh}$ in 2016 [16] with an average value of the electrical mix of $306 \mathrm{gCO}_{2} / \mathrm{kWh}$ in 2016 [17] which is still quite far from the targets of specific emissions established for $2020\left(207-218 \mathrm{gCO}_{2} / \mathrm{kWh}\right)$ [18]. Regarding the energy dependence of the country, external dependency in 2016 represented $72.3 \%$ of gross primary energy versus the average value in Europe set in 50\% [19].

Therefore, the development of improved energy storage technologies is especially relevant to exploit the greatest amount of the renewable potential in the country without introducing instabilities in the future renewable electric system. 
The objective of this study is to quantify the renewable power and Power-to-Gas capacities required to decarbonize and denuclearize the energy mix of the Spanish electricity system under different energy scenarios. The technology used for electric power production varies in each scenario to increase the decarbonization and denuclearization of the system.

\section{Energy scenarios: Scope and limitations of the study}

In literature, several studies quantify Power to Gas potential under future scenarios of national energy systems in which RES installed capacity is high enough to frequently lead to electricity surplus situations [20-23]. However, when these scenarios are tried to be foreseen, the strong uncertainty coming from economics, regulatory policies and technology evolution leads to disputable results. Thus, the attempt of defining an accurate estimation of future installed capacities such as those annually predicted by international organizations [24] mainly based on economic, political and technologic situation is discarded in this study, and a similar approach to that followed by Guandalini et al. [25] and Colbertaldo et al. [26] is applied instead.

Guandalini et al. looked for the upper technical limit of installed power for each non-dispatchable technology since long-term energy systems will ideally make the most from their resources, and therefore will tend to reach the maximum installation potential. Considering geographical and climate constraints together with the development of the state of the art in technology, the maximum reasonable power capacity for a given region may be estimated (Table 1) $[12,13,15]$. Wind and photovoltaic are those non-dispatchable technologies with larger growing potential and, therefore, those considered to define the scenarios under study. The possibility of decarbonizing and denuclearizing the Spanish electrical mix under different technological scenarios through the penetration of massive wind and photovoltaic energy sources is assessed. Then, results of wind and PV installed capacities are compared with the technical maximum as a measure of its feasibility.

Table 1. Technical potential in Spain.from different studies

\begin{tabular}{|l|c|c|}
\hline \multirow{3}{*}{ Technology } & Technical potential [GW] & References \\
\cline { 2 - 3 } Wind & 392.95 & {$[12]$} \\
\cline { 2 - 3 } & 340.00 & {$[13]$} \\
\hline Photovoltaic & $151.00-332.00$ & {$[14]$} \\
\hline
\end{tabular}

Electric demand is assumed to keep constant and similar to the current situation. Although the electrical demand has slightly grown in the last years in Spain (annual growth of $0.7 \%$ in 2016 and $1.2 \%$ in 2017 [27]), the trend in European countries is the conservation or slight decrease of 
demand as a consequence of energy efficiency improvements and limited economic growth. As an example, total net electricity generation in the EU-28 in 2015 was $4.5 \%$ lower than its relative peak of 2008 [28]. Therefore, it must be kept in mind that the results obtained from this study will be valid in case this assumption is fulfilled.

Thus, this study is conducted using the electric demand data and hourly distribution corresponding to 2016 (last reported data by Spanish transmission system operator) which is considered the reference year [17]. This demand is covered through a combination of base power (CHP and nuclear power), non-dispatchable power (small hydroelectric, geothermal, concentrated solar, wind and photovoltaic) and back-up technologies.

\subsection{Current Spanish scenario and selected technical potential for wind and PV power}

Firstly, current situation of the Spanish electrical mix must be analysed to better understand the motivation and justification of some of the assumptions included in this analysis. The main technologies included in the mix have been divided (i) base load (nuclear and cogeneration), (ii) non-dispatchable RES (hydro, geothermal, concentrated solar, wind, photovoltaic) and (iii) backup technologies (fossil fuels and dispatchable technologies such as biomass power plants).

Regarding base power, there are not planned projects for increasing current nuclear capacity in the mid-term (7.8 GW). The seven existing plants commissioned between 1983 and 1988 still participate in the energy market with capacity factors around $90 \%$. All these plants should shut down in the near future but given their high share in the energy mix they will probably get granted with 10-year lifetime extensions by favorable reports from the authorities $[29,30]$. Thus, we consider a constant nuclear power capacity in the study.

The decarbonization of industry also represents a hot topic in Europe and the implications of changes in CHP for future EU electricity demand will be relevant [31]. CHP operates at full load most of the time and cannot be regulated, since over 600 companies (mostly chemical, paper, and food industries) produce 50\% of CHP power production. Because of the 2008 financial crisis, the production was slowed down, and therefore the Spanish CHP association expects that installed capacity remains constant at $6.7 \mathrm{GW}$ for the next years [32]. So, we consider that CHP installed capacity, operating hours and distribution throughout the year keep unchanged from 2016 data. This trend has been also checked with accumulated data in 2017 [17].

With regard to non-dispatchable technologies, hydropower is a well consolidated technology in Spain with $20.6 \mathrm{GW}$ of installed capacity. This value is already close to its maximum potential estimated to be near $33 \mathrm{GW}$ [33]. Large projects are not expected to occur in mid-term, while forecast indicates a moderate increase of installed power by repowering existing plants or powering irrigating dumps. Thus, hydropower may be considered constant in our scenarios. 
146 Geothermal resource is scarce in Spain and so do its share in the energy mix. Conservative 147 prospective studies account only for near $83 \mathrm{MW}$ of new installation by 2020 [13], therefore we 148 may assume that geothermal capacity keeps constant in the mid-term also.

149 Regarding concentrated solar power, no new projects are expected since incentives have been cut. 150 So, even though the national renewable energy action plan (NREAP) envisaged CSP capacity of 1515 GW by 2020 [34], we do not consider any growth in the installed capacity.

152 As stated, base load and part of non-dispatchable renewable technologies are not expected to 153 significantly grow and their contribution will be much less important in the share of electric 154 generation than wind or photovoltaic contribution. As a simplification, the decarbonization 155 process - and the potential denuclearization - of electricity production is assumed to be conducted by increasing wind and photovoltaic installed power, since they represent the main renewable sources in Spain and have the greatest growth potential (Table 1).

The maximum potential deployment of wind power in Spain has been valued between 151-393

159 GW [12-14]. The most reliable model was that developed in the framework of RESHAPE project

160 [12] which considers two main factors of influence in the estimation of available wind energy 161 potential: (i) the local wind regime influencing the energy yield of a turbine, and (ii) the land area available for construction of wind turbines which determines the total available wind capacity potential. Thus, the selected maximum potential considered in this study is $393 \mathrm{GW}$ which is still far from the current installed capacity of $22.5 \mathrm{GW}$.

When dealing with photovoltaic power, the estimation of the technical potential becomes quite complex, since the available surface depends on many variables. A reduced number of comprehensive studies have been published so far [13], from which the most reliable data are those of IEA's reports [15]. Based on the estimated available surfaces on buildings and ground $\left(617 \mathrm{~km}^{2}\right)$, the technical potential results in about $66.51 \mathrm{GW}$ of installed photovoltaic systems. Finally, the back-up power required to cover electrical demand beyond base load and nondispatchable sources includes fossil conventional thermal plants (coal and gas) and renewable energy sources such as biomass or biogas and waste. Current installed capacity of controllable 173 and adjustable back-up technologies rises up to $91 \mathrm{GW}$ : $46 \mathrm{GW}$ coal thermal plants, $39 \mathrm{GW}$ 174 natural gas combined cycles, around 2.5 GW biomass and biogas facilities and 3.5 GW waste 175 facilities [27].

176 The increase of wind and photovoltaic power capacity aims to replace current fossil fuels-based 177 backup technologies (coal and natural gas, $85 \mathrm{GW}$ ), partially decarbonizing the energy mix. This 178 decarbonization is supported by the utilization of synthetic natural gas produced by means of 
179 Power to Gas facilities which absorb surplus electricity from non-dispatchable RES and manage

180 the availability of this energy later in time.

181

182

183

184

185

186

187

188

189

190

191

192

193

194

195

196

197

198

199

200

201

202

\subsection{Proposed scenarios}

After providing basic information on the electrical mix trends and situation, the three possible scenarios that will be analyzed in this work are defined in the following paragraphs. The first studied framework denoted as Scenario 1 (Table 2) quantifies the growth of wind and PV installed capacity and the required Power-to-Gas capacity needed to completely decarbonize the backup power system of Spain. The back-up technologies, Gas Turbines (GT) and Combined Cycles (CC) required under this scenario are fed by synthetic fuel $\left(\mathrm{H}_{2}\right.$ or $\left.\mathrm{CH}_{4}\right)$ produced from the surplus renewable electricity through PtG facilities.

In a second scenario (Scenario 2), decarbonization is extended to also cover the CHP technology. Under this scenario, conventional CHP is considered to be fed by renewable synthetic fuel generated by PtG. It is assumed that CHP technologies will present the same hourly production patterns since they are associated to socioeconomic factors which are expected to remain constant. Thus, the required increase of wind, photovoltaic and $\mathrm{PtG}$ capacities are quantified in order to have enough available electricity excess to fulfill both backup and CHP's fuel requirements. In these two first scenarios, four cases are evaluated (Table 2). Each of these cases accounts for one specific synthetic fuel and one single transformation technology.

A third scenario (Scenario 3) is analyzed, in which backup and CHP conventional technologies are substituted by fuel cells fueled with $\mathrm{H}_{2}$ from surplus renewable electricity. The growth of Power-to-Gas technology will be significantly different from Scenario 1 and 2 given the greater efficiency of the reconversion technology. Besides, the heat to electricity production ratio of fuel cells highly differ from conventional CHP technologies.

Table 2. Scenarios under study to decarbonize the electrical Spanish system.

\begin{tabular}{|c|c|c|c|}
\hline & Scenario 1 & Scenario 2 & Scenario 3 \\
\hline \multicolumn{4}{|l|}{ Electrical demand } \\
\hline Reference year 2016 & Constant demand \& pattern & Constant demand \& pattern & Constant demand \& pattern \\
\hline \multicolumn{4}{|l|}{ Base load } \\
\hline $\mathrm{CHP}^{1}$ & $\begin{array}{r}\text { Conventional } \\
\text { based on fossil fuel }\end{array}$ & $\begin{array}{l}\text { Conventional } \\
\text { based on PtG }\end{array}$ & $\begin{array}{r}\text { Fuel Cell } \\
\text { based on PtG }\end{array}$ \\
\hline Nuclear $^{2}$ & Conventional & Conventional & Conventional \\
\hline \multicolumn{4}{|l|}{ Non-dispatchable } \\
\hline Wind & Growing capacity & Growing capacity & Growing capacity \\
\hline $\mathrm{PV}$ & Growing capacity & Growing capacity & Growing capacity \\
\hline CSP & Constant capacity & Constant capacity & Constant capacity \\
\hline Hydroelectric power & Constant capacity & Constant capacity & Constant capacity \\
\hline Geothermal power & Constant capacity & Constant capacity & Constant capacity \\
\hline \multicolumn{4}{|c|}{ Backup power (based on PtG) } \\
\hline GT based on $\mathrm{H} 2$ & Case A & Case A & - \\
\hline CCGT based on $\mathrm{H} 2$ & Case B & Case B & - \\
\hline GT based on $\mathrm{CH} 4$ & Case $\mathrm{C}$ & Case $\mathrm{C}$ & - \\
\hline
\end{tabular}




\begin{tabular}{|l|r|r|r|}
\hline CCGT based on CH4 & Case D & Case D & - \\
\hline Fuel Cell based on $\mathrm{H} 2$ & - & - & Case E \\
\hline
\end{tabular}

$204 \quad{ }^{2}$ Nuclear installed capacity and operation factor are considered constant.

205 Additionally, the study assesses the possibility of denuclearizing the energy system, under the 206 framework of these three scenarios. The energy produced by nuclear power would be replaced 207 also by wind, PV and renewable backup, so the required installed capacity drastically growth. 208 The closer to the technical upper limit, the more limited feasibility of deployment for each case.

\section{Methodology of PtG capacity calculation}

210 Once the target of each scenario and the conditions of the considered cases have been defined, 211 the steps which have been followed to obtain the results are presented in this section. Figure 2 212 illustrate the flowchart with initial data sources (elliptic boxes), the data management (rounded 213 boxes), the final calculated variable (square boxes) and the conditions for scenarios and cases 214 (rhomboid boxes).

215 The surplus electricity was defined and calculated for previous years with historical data. 216 Obtained values show similar requirements of back-up electricity and surplus energy for similar 217 installed capacities. Thus, the hourly distribution of the operation of different generation 218 technologies along the year leads to similar behaviors when the annual timeframe is considered. 219 This will be used to establish a reference hourly distribution pattern for wind and photovoltaic 220 technology which will be used in the estimation of surplus energy in future situations. Hourly 221 demand, base power production and CSP/hydroelectric/geothermal production are directly taken from 2016 data.

223 Only wind and photovoltaic power are considered to grow in future scenarios to decarbonize the 224 system. So, first we calculate the wind and photovoltaic production by using the hourly 225 distribution derived from 2016 data and a given installed capacity. Then, the balance of the 226 electricity system is computed to estimate surplus electricity periods and back-up requirements at 227 every hour in prospective scenarios. The method used to derive the optimal PtG capacity for a 228 specific scenario is explained through the use of the duration curve of the surplus electricity.

229 Once PtG is sized, the stored energy is analysed to determine the potential to match deficiency 230 situations according to the selected scenario of decarbonization, back-up technology used, and 231 synthetic fuel produced. Whenever a mismatch exists, the wind and PV installed capacity are modified (iterative calculations). 


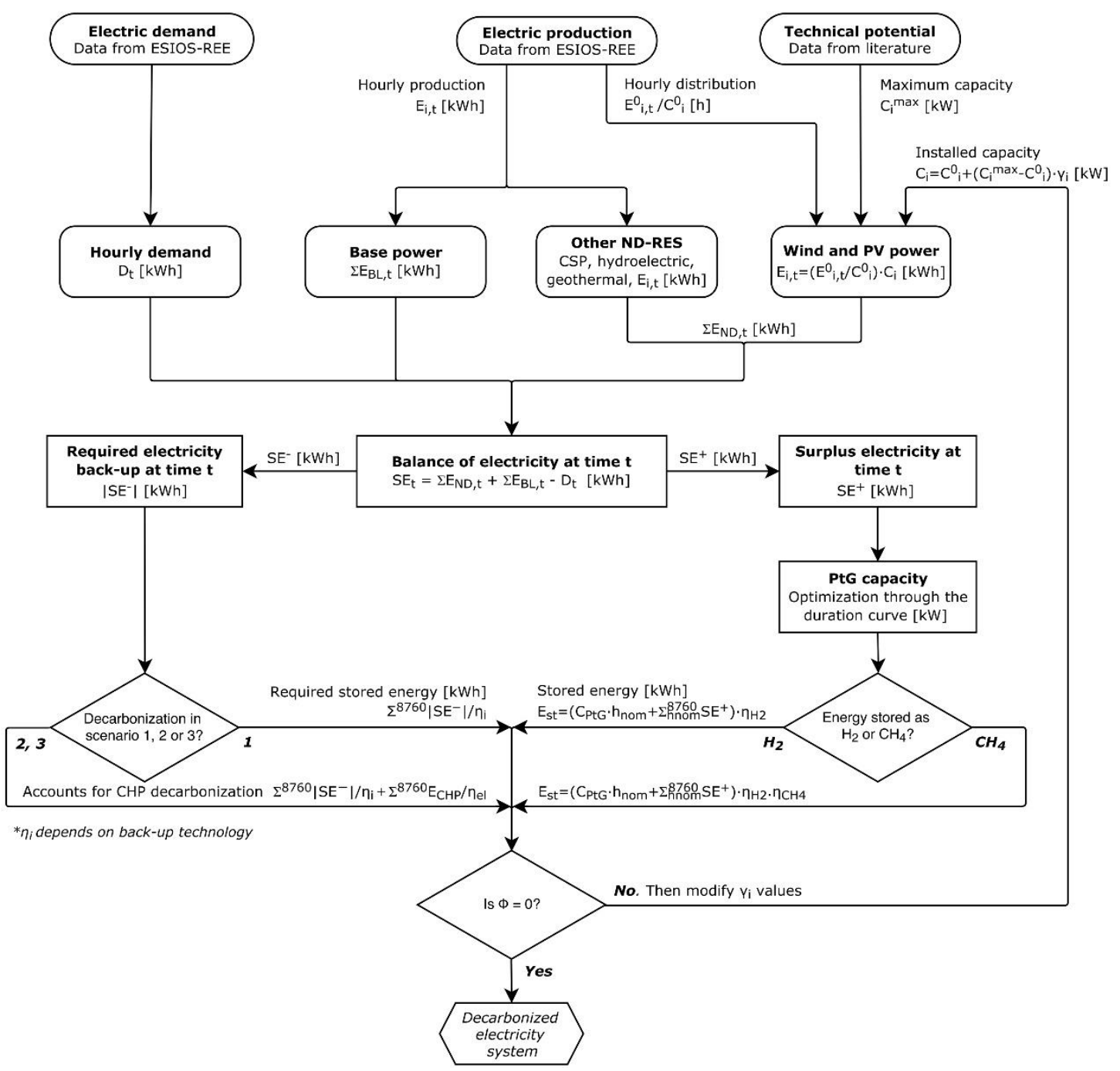

Figure 2. Flowchart of the methodology used for calculation of PtG capacity under proposed scenarios

\section{3.1. Balance of energy definition}

236 The energy balance is defined in Eq. 1 to determine whether an electricity system with high renewable sources penetration will require the operation of dispatchable electricity conventional sources to complete the coverage of the demand or the operation of energy storage technologies.

$$
B E_{t}=\sum E_{N D, t}+\sum E_{B L, t}-D_{t}
$$

240 This energy balance definition, $B E_{t}$, compares the production from base-load energy sources, $241 \sum E_{B L, t}$, and non-dispatchable energy sources, $\sum E_{N D, t}$, with the hourly electrical demand, $D_{t}$. 242 Between 2014 and 2016, annual Spanish electrical demand remained almost constant and ranged 243 243-249 TWh/year. The non-dispatchable sources will include different climate-dependent 244 technologies. To calculate the potential surplus of energy those technologies which are included 245 in the base load must be also considered. In Spain, the base load consists of electrical generation 246 from CHP which is related to industrial production following its own patterns and nuclear 
247 generation. Nuclear operates over 7200 hours per year providing an average of $22.2 \%$ of total

248 electricity production in 2016 [17].

249 The back-up power of the system will be required to complete the coverage of the electrical 250 demand whenever this variable takes a negative value, namely $B E^{-}$. The back-up technologies 251 include coal, gas and biomass or waste traditional thermal power plants. In those periods in which 252 base load and non-dispatchable generation surpass the total demand, the balance becomes positive $253 B E^{+}$, and surplus electricity may be directed. Power to Gas is the only storage technology taken 254 into consideration in this study since its order of magnitude (GWh-scale) and the country-level 255 analysis leave apart from the discussion the low energy capacity equipment. Other large-scale 256 storage equipment, such as hydro pumping, are also out of the scope of the study since they have 257 mostly achieved their maximum capacity.

258 From data provided by Spanish Electrical Grid (Red Eléctrica Española) in its Transparency 259 Report [17] and the definition of energy balance from Eq. 1, the hourly energy balance has been 260 calculated for the three set of available data (2014. 2015 and 2016) to detect deviations. An 261 analysis of data between 2014 and 2016 [17] concluded that a statistical treatment cannot be 262 applied since most relevant information for our study which is related to the peak situations would 263 be eliminated. It can be seen in Table 3 that annual values of back-up requirement, $\left|B E^{-}\right|$, and 264 excess electricity, $B E^{+}$, present the same order of magnitude in the past years. Since energy 265 demand and production are influenced by several different factors, it is natural to observe a certain 266 degree of fluctuations, like those highlighted in Table 3. From this perspective could be very 267 challenging to predict the exact amount of required PtG capacity since the forecasting of the exact 268 RES production patterns for the forthcoming years is extremely difficult.

269 Current Spanish energy scenarios do not present surplus energy large enough to propose the 270 installation of PtG technologies as a solution to decarbonize any sector. The annual excess varies 271 from 160-560 GWh distributed along the whole territory with a peak power between 2.7-5.6 GW 272 [17]. These current figures do not make attractive the massive deployment of this technology, but 273 the energy system continuously evolves, and the future energy scenario is expected be extremely 274 different.

\begin{tabular}{|c|c|c|}
\hline & $\begin{array}{c}\left|\boldsymbol{B} E^{-}\right| \\
{[\mathbf{T W h} / \mathbf{y}]}\end{array}$ & $\begin{array}{c}\boldsymbol{B E}^{+} \\
{[\mathbf{T W h} / \mathbf{y}]}\end{array}$ \\
\hline $\mathbf{2 0 1 4}$ & 65,88 & 0,36 \\
\hline $\mathbf{2 0 1 5}$ & 81,92 & 0,16 \\
\hline $\mathbf{2 0 1 6}$ & 75,99 & 0,56 \\
\hline
\end{tabular}


In this work, potential scenarios with a higher penetration of RES which may make PtG attractive will be defined by means of the procedure described in the following paragraphs. Once the required variables are assumed or estimated under these new scenarios the surplus energy will be calculated as described in this section, Equation 1.

\subsection{Hourly distribution of non-dispatchable RES production}

As shown in Figure 2, one of the first steps is the determination of the hourly distribution of wind and photovoltaic sources. This distribution will be used in the calculation of their electricity production along the year, $E_{i, t}$, in the different scenarios.

The hourly distribution of electric demand throughout the year, $D_{t}$, is considered to follow a constant pattern. Also, constant patterns of climate-dependent renewable energy sources are expected along the years. Therefore, the hourly distribution of wind or PV energy generation along the year, $E_{i, t}$, in future scenarios may be linearly scaled. In this study, the reference hourly pattern is assumed the same than year 2016, and then the generation is scaled up following Eq. 2, where $C_{i}$ is the proposed installed capacity of the model [25].

$$
E_{i, t}=\frac{E_{i, t}^{0}}{C_{i}^{0}} \cdot C_{i}
$$

The $E_{i, t}^{0} / C_{i}^{0}$ factor represents the hourly pattern, i.e., the equivalent operating hours of technology $i$, at time $t$, for a selected reference year. It is known that wind power production behaves as a chaotic system, and therefore the instantaneous values of $E_{i, t}^{0} / C_{i}^{0}$ highly differ from one year to another. Nevertheless, the aggregated values of wind power production in previous years $(2014$, 2015 and 2016) presented in section 3.1 give similar global outputs when the whole year is accounted. This assumption is essential to scale-up the hourly distribution along the year of RES generation. Therefore, it is considered that 2016 pattern is representative and the distribution and number of hours of operation have been calculated through equation 2, taking as reference year 2016.

This approach is only focused on photovoltaic and wind production. This analysis is based on data of hourly production and load profiles available from transmission system operator websites, ESIOS - Red Eléctrica Española (Transparency reports, European Regulation 1228/2013) [17].

\subsection{Variation parameters to modify installed non-dispatchable RES power}

Besides the distribution of operating hours along the year $\left(E_{i, t}^{0} / C_{i}^{0}\right.$ section 3.2), to estimate the electricity production of wind and solar sources, $E_{i, t}$, their installed capacity in the analysed scenarios, $C_{i}$, must be addressed. Most of the existing studies are focused on market evolution and affected by economic and regulation. However, a more global analysis of RES technical potential should not take into account these aspects, but only limitations due to available resources 
and environment safeguard. A review of available data in literature considering the technical potential is summarized in Table 2. From these studies, values considered as more reliable are 392.95 GW for wind power [12] and 66.51 GW for photovoltaic installed power [15]. These figures are used in the following as maximum installed capacity.

To express the installed capacity of wind and photovoltaic under each scenario, two new variables are defined, $\gamma_{w}$ and $\gamma_{p v}$, as presented in (Eq. 3):

$$
\left\{\begin{array}{l}
\gamma_{w}=\frac{C_{w}-C_{w}^{0}}{C_{w}^{\max }-C_{w}^{0}} \\
\gamma_{p v}=\frac{C_{p v}-C_{p v}^{0}}{C_{p v}^{\max }-C_{p v}^{0}}
\end{array}\right.
$$

These equations compare the productive installed capacity considered in our study, $C_{i}$, with maximum achievable installed capacity, $C_{i}^{\max }$, and current productive capacity, $C_{i}^{0}$. In this way, the percentage of increase over the current installed capacity (reference year, 2016) with respect to the maximum possible increase of installed capacity is defined. The modified capacity can now be calculated from (Eq.3) as expressed in (Eq.4):

$$
\begin{gathered}
C_{w}=C_{w}^{0}\left[1+\frac{\left(C_{w}^{\max }-C_{w}^{0}\right) \gamma_{w}}{C_{w}^{0}}\right] \\
C_{p v}=C_{p v}^{0}\left[1+\frac{\left(C_{p v}^{\max }-C_{p v}^{0}\right) \gamma_{p v}}{C_{p v}^{0}}\right]
\end{gathered}
$$

\subsection{Surplus energy estimation}

The terms of (Eq.1), $E_{i, t}$, correspond to existing values in the case of historical calculations. When new scenarios are to be defined these terms must be estimated based on (i) existing values (reference year) and on (ii) prospective installed power. As presented in section 3.2, current values are used to define electric demand and the distribution of operating hours of non-dispatchable technologies. Prospective installed power will be estimated depending on the specific case to study as presented in section 3.3.

The installed power capacity of wind and photovoltaic sources in the scenario under study is represented by $C_{i}$ and its value will be always below the technical potential. The model, through Eq. 2, assumes a constant distribution of the equivalent operating hours for the technologies. The reference value of installed capacity and the reference generation distribution are considered to be those of 2016 .

The negative values of energy balance will determine the requirements of back-up power capacity in the system while the positive values of the surplus energy indicates the amount of annual energy available for storage. As seen back-up power is not a priori defined in the model but calculated 
as hourly back-up amount of energy. In this study focused on the decarbonization of electricity production, considered back-up technologies will be those fed by hydrogen or synthetic natural gas from PtG and based in RES. For the sake of simplicity and given the small share of biomass and biogas fed power plants, the back-up technology has been considered homogeneous for each studied scenario: gas turbine thermal plants, combined cycles thermal plants and fuel cells.

The surplus energy may be stored as valuable fuel gas (hydrogen or synthetic natural gas) in the natural gas grid and be used in the proper moment and location to provide electricity or to cover thermal demand, Figure 1.

\subsection{Duration curve and optimal PtG installed power}

Once the hourly availability of surplus energy is determined through the calculation of $B E_{t}$ (Eq.1), the optimal PtG capacity must be defined. To determine the recommended installed capacity of PtG under each scenario the load duration curve is built and the PtG capacity will be obtained by choosing a minimum number of 1000 operating hours in x-axis, Figure 3.

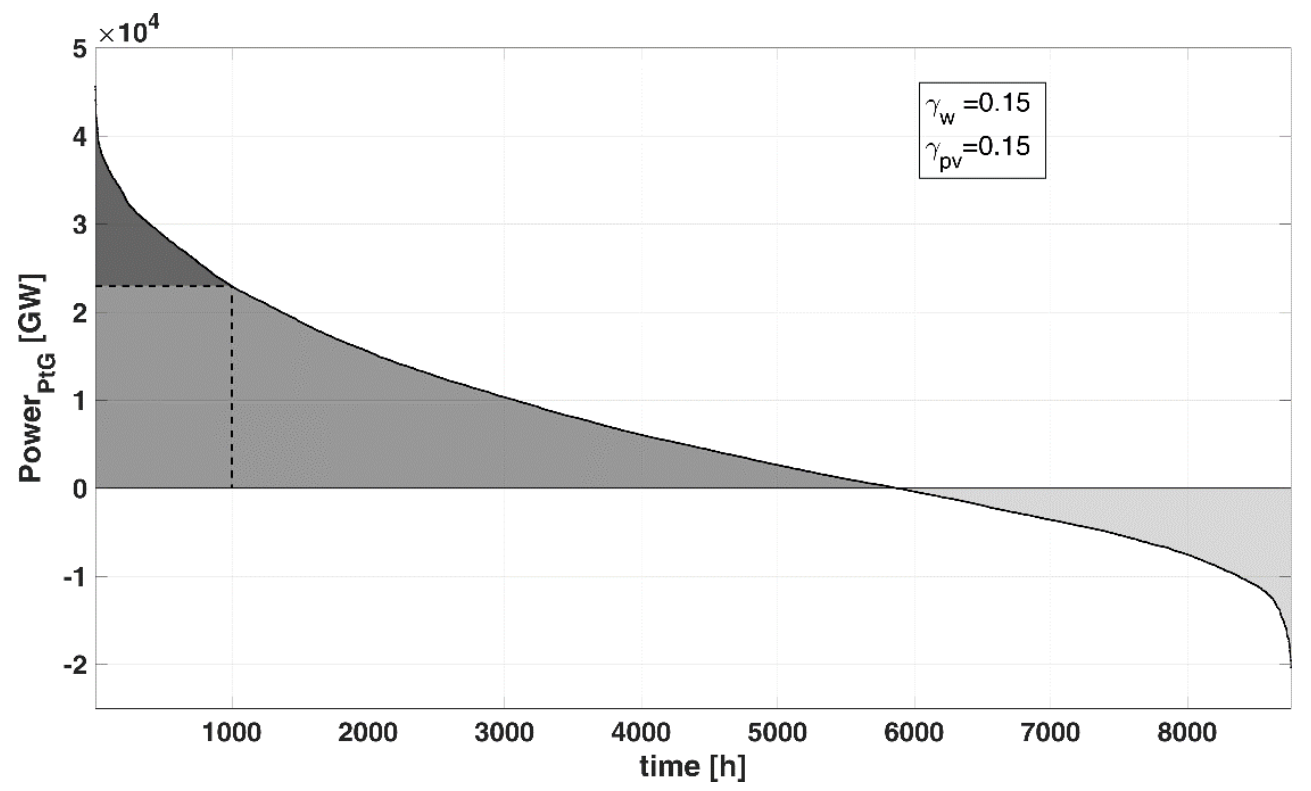

Figure 3. Duration curve with the energy available for the $P t G$ (medium grey) and the dumped energy (dark grey)

The hourly energy surplus $\left(B E_{t}^{+}\right)$is sorted in descending order to obtain the duration curve. On the duration curve, choosing the amount of hour at which the PtG must be able to work at full capacity, the PtG nominal power to be installed can be calculated. As reported in Figure 3, the choice of $h_{\text {nom }}$ determines not only the PtG installed capacity, but also the amount of energy that can be harvested (grey-shaded area) and the energy that has to be dumped (dark grey-shaded area).

\subsection{Renewable fuel production and back-up coverage calculation}


Once the PtG capacity is obtained from the duration curve of surplus energy, the amount of energy stored as hydrogen or methane and the electricity produced from these synthetic renewable fuels using three different technologies gas turbine cycles, combined cycles and fuel cells may be calculated.

The amount of surplus energy stored as $\mathrm{H}_{2}$ (Eq. 5) or $\mathrm{CH}_{4}$ (Eq. 6) can be calculated from the greyshaded area in Figure 3, by multiplying such area which corresponds to the electricity that can be handled by the PtG system by the efficiency of electrolysers and the efficiency of methanation process.

$$
E_{s t}^{H_{2}}=\left(C_{P t G} \cdot h_{n o m}+\sum_{\tau=h}^{8760} B E_{t}^{+}\right) \cdot \eta_{H_{2}}
$$

$$
E_{s t}^{C H_{4}}=E_{s t}^{H_{2}} \cdot \eta_{C H_{4}}
$$

371 The energy available to storage is calculated through the installed PtG capacity, the hours operating at nominal load and the positive values of surplus energy. In this study, alkaline electrolyzer with efficiencies around $70 \%$ are considered [35] and the average efficiency of methanation process found in literature is $80 \%$ [9,36,37]. Depending on the case of study (Table 2), (Eq. 5) or (Eq. 6) should be used.

\subsection{Determination of RES installed capacities}

377 Calculations presented in sections 3.2 to 3.6 are carried out for several production mix combinations where wind and photovoltaic power are gradually increased as described through equations (Eq. 3) and (Eq. 4). However, the target of the study is the determination of the new installed capacity of wind and photovoltaic power required to fulfil the conditions established for each scenario: (i) coverage of back-up by conventional technologies, (ii) coverage of back-up and CHP by conventional technologies and (iii) coverage of back-up and CHP by fuel cell technology.

$\underline{\text { Scenario } 1}$

The target in Scenario 1 (SC1) is to assess the amount of photovoltaic and wind power additional capacity that must be installed to cover the demand that is not instantaneously covered by based load and non-dispatchable RES technologies without resorting to traditional fossil-fuel plants. Negative values of energy balance, $B E^{-}$, show these periods in which electrical demand is not covered by base load and non-dispatchable RES.

A new variable, which discriminate whether the decarbonation condition defined for each scenario is fulfilled or not, is defined through equation (Eq. 7).

$$
\left.\phi_{j}^{f u e l}\right|_{S C 1}=E_{s t}^{f u e l}-\frac{\sum_{t=1}^{8760}\left|B E_{t}^{-}\right|}{\eta_{j}}
$$


This variable will provide different results depending on the gaseous synthetic fuel considered (fuel: $\mathrm{H}_{2}$ or $\mathrm{CH}_{4}$ ) and the technology chosen to convert the gas fuel back into electricity ( $j$ : GT or CCGT).

When $\Phi$ is equal to zero in Scenario 1, the energy stored as synthetic fuel is able to perfectly cover on an annual basis the electrical back-up needs of the system. Conversely, negative values of $\Phi$ indicate that the chosen combination of wind and photovoltaic installed capacities does not originate a suitable surplus energy pattern and a PtG capacity which are able to make the back-up system independent from conventional production plants. Finally, the situations in which positive values $\Phi$ are found correspond to those in which the RES production, jointly with the PtG, stores more energy than the needed to cover back-up power.

\section{$\underline{\text { Scenario } 2}$}

The target in this scenario (SC2) is to define the installed capacities of wind and photovoltaic power required to completely decarbonize the electrical mix. Synthetic fuel produced by PtG from surplus energy will be used to cover the back-up requirements and the CHP power installed in the country.

Thus, the only difference in the calculation of $\Phi$ for this second scenario will be the consideration of CHP installed capacity which is assumed to remain constant in future situations. Since chemical energy that power the CHP will be taken from the energy stored by the PtG as hydrogen or methane, the equation (Eq.7) must be modified as follows (Eq.8):

$$
\left.\phi_{j}^{f u e l}\right|_{S C 2}=E_{s t}^{f u e l}-\left(\frac{\sum_{t=1}^{8760}\left|B E_{t}^{-}\right|}{\eta_{j}}+\frac{\sum_{t=1}^{8760} E_{C H P}}{\eta_{e l}^{C H P}}\right)
$$

The used fuel can be either $\mathrm{H}_{2}$ or $\mathrm{CH}_{4}$ and the used technology to reconvert gas fuel into electricity can be gas turbine or combined cycle. The interpretation of the values obtained for $\Phi$ is the same presented in the previous subsection.

\section{$\underline{\text { Scenario } 3}$}

The target in Scenario 3 (SC3) is the same of SC2; to cover back-up generation and CHP electric production without fossil-fuels. Therefore, the criteria and equation used to determine the installed capacity of wind and photovoltaic (Eq. 8) to cover both back-up and CHP with renewable synthetic gas.

The difference resides in the technologies used to generate back the electricity. Scenario 3 considers that fuel cell technologies are used in both back-up technologies and CHP. In the case of back-up fuel cells technologies, this modification affects to the second term in equation (Eq. 8) through the efficiency in the denominator. The value of conversion efficiency of fuel cell 
systems is accounted to be 0.6 which is slightly lower than nominal values to consider the effect of part load operation.

427 With regard to fuel cell technology applied to CHP, the amount of thermal energy produced is 428 kept constant while the electric and thermal efficiencies differ from conventional technologies.

429 The new CHP electric production (high temperature fuel cell) will be related to the old values 430 (conventional technologies) to maintain the same annual trend, following the equation (Eq. 9). 431 This $E_{C H P}^{n e w}$ should replace the previous energy production of CHP in the balance of energy (Eq. 432 1), which is accounted in the base load term.

$$
E_{C H P}^{\text {new }}=E_{C H P}^{\text {old }} \cdot\left(\frac{\eta_{\text {th }}}{\eta_{\text {el }}}\right)_{\text {old }} \cdot\left(\frac{\eta_{e l}}{\eta_{\text {th }}}\right)_{\text {new }}
$$

\section{4. Results and discussion.}

435 Once presented the methodology to calculate those variable that determines the availability of energy surplus and the optimal PtG capacity to be installed, results may be obtained for each scenario and discussed.

\subsection{Scenario 1: Back-up coverage through conventional power technologies}

As described in section 2.2, under Scenario 1 the energy stored from PtG facilities will be used to cover the electrical load provided by back-up technologies. Therefore, the traditionally fossilfuel fed back-up technologies are substituted by dispatchable energy technologies fed by renewable synthetic fuel gas. These dispatchable technologies will be gas turbine cycles and combined cycles fed by hydrogen or methane from PtG.

444 The results related to the PtG capacity, the energy stored as $\mathrm{H}_{2}$ and the energy that cannot be 445 harvested by the installed PtG capacity for different situations of installed capacities of wind and 446 photovoltaic power are mapped in Figure 4. The situations analysed under this scenario varies from current situation in Spain (2016 as reference year) with regard to wind and photovoltaic installed power which corresponds to the values at point $(0,0)$ to an increase of the presence of both technologies up to a $50 \%$ of the theoretically maximum, point $(0.5,0.5)$. As stated in section 1, current wind and photovoltaic installed power in Spain are $22.8 \mathrm{GW}$ and $4.4 \mathrm{GW}$ while the maximum installed power considered in Figure 4 are $157.87 \mathrm{GW}$ and $35.45 \mathrm{GW}$, respectively.

The PtG installed capacity varies from $0.4 \mathrm{GW}$ under current situation $(0,0)$ where energy surpluses are rarely found in the electric market as pointed out in Table 1 to $82.4 \mathrm{GW}$ under the energy mix with the highest wind and photovoltaic penetration. These values are obtained from the duration curve built for each $(x, y)$ energy mix situation. 

to $242 \mathrm{TWh}$ which corresponds to near a $17 \%$ of the total primary energy consumed in the country in 2016 [38].
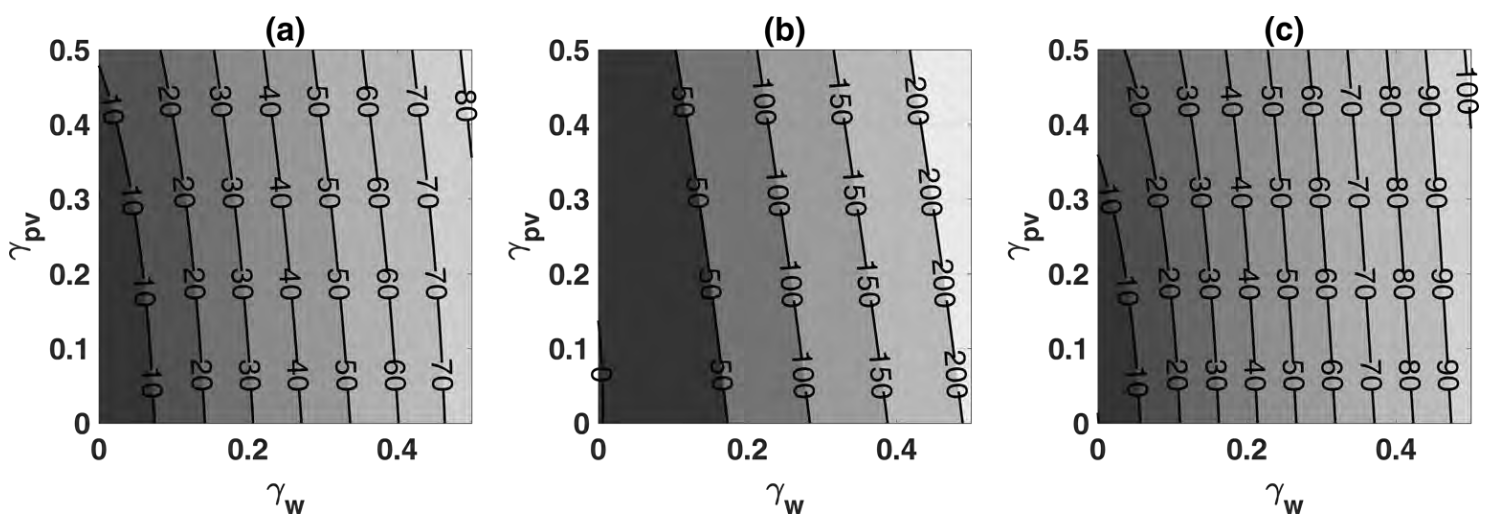

459

460

461

462

463

464

465

466

467

468

469

470

471

472

473

474

475

476

477

Figure 4. (a) PtG capacity [GW]; (b) Energy stored as H2 [TWh]; (c) Dumped energy [TWh].

Although energy stored as $\mathrm{CH}_{4}$ is not presented, it can easily be calculated from the trends reported in Figure 4 (b) by multiplying by the efficiency of the methanation process as indicated in Eq. 6.

Part of the surplus energy will be lost due to the chosen size of the PtG system which will may not be able to absorb some of the production peaks. As an example, while chosen PtG capacity in the most extreme RES penetration situation is $82.4 \mathrm{GW}$, the maximum available power may reach $152 \mathrm{GW}$. This value lead to an annual energy availability up to $101.6 \mathrm{TWh}(7 \%$ of the primary energy consumed in Spain in 2016) which could not be processed by PtG installed capacity. This energy could be stored by means of other storage technologies depending on the amount and hourly distribution.

The main target of this study is to find out the coverage of electrical demand by means of renewable energy which might be chemically stored through PtG systems and later used to generate electricity through conventional cycles but using a decarbonized fuel. The stored fuel presented in Figure 4 (b) can be reconverted back into electric energy to cover the back-up necessities by means of several technologies such as gas turbines, combined cycles and, only for hydrogen, fuel cells.

The conversion efficiency for the gas turbine cycles is assumed to be equal to 0.3 , while in the case of combined cycles the value is 0.5 . These efficiencies are lower than the generally accepted nominal values to consider the effect of part load functioning. While the use of gas turbine and combined cycles promotes an integration between the current productive fleet $(24.91 \mathrm{GW}$ current installed capacity of combined cycles in Spain [27]), to massively use fuel cell technologies would require a deep overhaul of the productive system. Thus, this last case (case E) will be analysed separately under Scenario 3. 
The results related with values of $\Phi$ are reported in Figure 5. Four combinations of stored synthetic fuel and electricity generation technology are presented (a) $\Phi$ for hydrogen and gas turbine cycles; (b) $\Phi$ for hydrogen and combined cycles; (c) $\Phi$ for methane and gas turbine cycles; (d) $\Phi$ for methane and combined cycles. From these results, back-up technologies required to cover electrical demand will be completely decarbonized by means of synthetic fuel generated through PtG technologies in the ranges of 4.4-35.45 GW of photovoltaic and 39-76.8 GW of wind power.

(a)

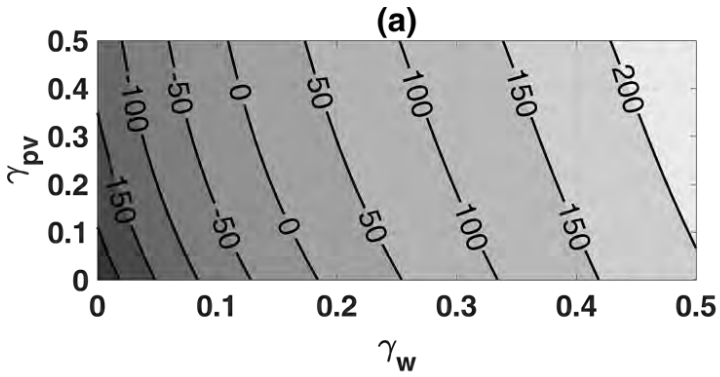

(c)

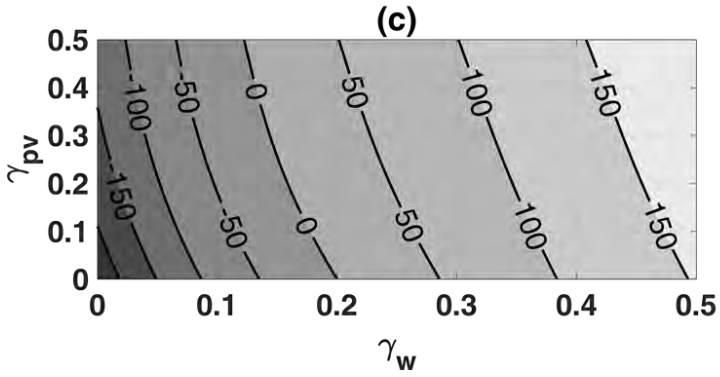

(b)

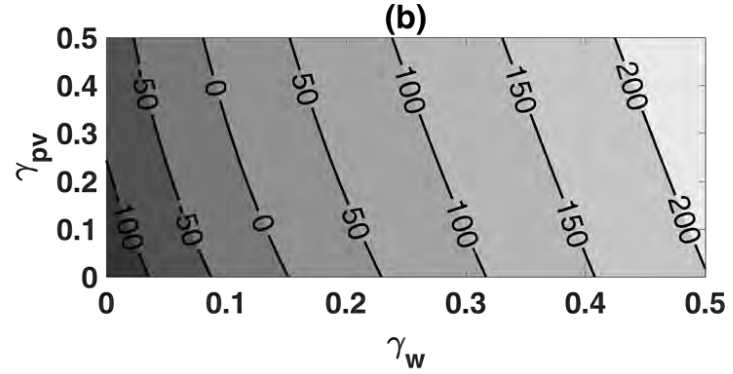

(d)

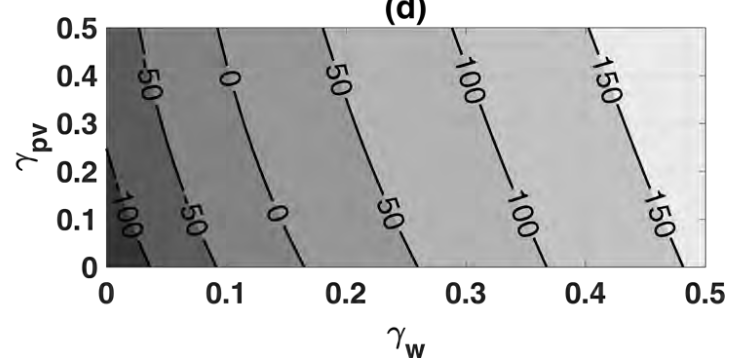

491

492

493

494

495

496

497

498

499

500

501

502

503

504

505

506

507

Figure 5. (a) $\Phi$ for $\mathrm{H}_{2}$ and GT; (b) $\Phi$ for $\mathrm{H}_{2}$ and CCGT; (c) $\Phi$ for $\mathrm{CH}_{4}$ and GT; (d) $\Phi$ for $\mathrm{CH}_{4}$ and $C C G T$.

The most favourable combination corresponds to the storage as hydrogen and the use of combined cycles in the electricity generation, while the most penalized combination from an energetic point of view corresponds to the storage as methane and the use of gas turbine cycles as electricity production technology. In general, the effect of increased efficiency of combined cycles compared to gas turbines and the penalty of $\mathrm{CH}_{4}$ production are observed in Figure 5.

\subsection{Scenario 2: Back-up and CHP coverage through conventional power technologies.}

The target established in Scenario 2 is to cover electricity from back-up and CHP technologies using the renewable synthetic gaseous fuel produced through PtG facilities. It can be assumed that average electric and thermal efficiencies of CHP correspond to current values in the CHP technologies of the country.

Using CHP electricity production data of the Spanish market between 2012-2016 [17], the average electric efficiency of CHP in Spain is calculated to be 0.33 , while the thermal efficiency is around 0.47. If those figures remain unchanged, so does the ratio between thermal and electric CHP production. This fact is highly relevant since the operation of CHP systems follows the thermal requirements of the end users and while the electric output is regulated consequently. 
Analogously to the previous scenario, the results obtained for $\Phi$ under Scenario 2 are reported in

509 Figure 6 for methane and hydrogen, and for the technologies gas turbine and combined cycle. It

510 is worth noting that these technologies are those used for the re-conversion of the fuel into

511 electricity when the PtG provides the electric storage service. They are not the technologies used

512 for the CHP, which, at this stage of the study, are characterized only by average electric and

513 thermal efficiencies.

514 Electricity back-up generation and conventional CHP technologies will be completely 515 decarbonized in the Spanish energy mix by means of using synthetic fuel generated through PtG 516 technologies when photovoltaic and wind power capacities increase in the country up to the 517 ranges of 4.4-35.45 GW and 71.4-109.2 GW, respectively.

(a)

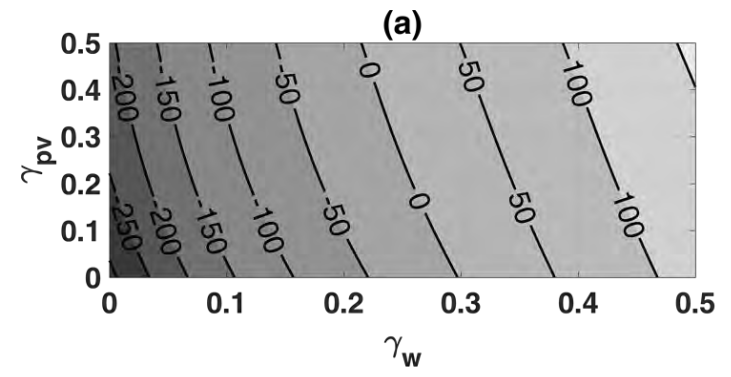

(c)

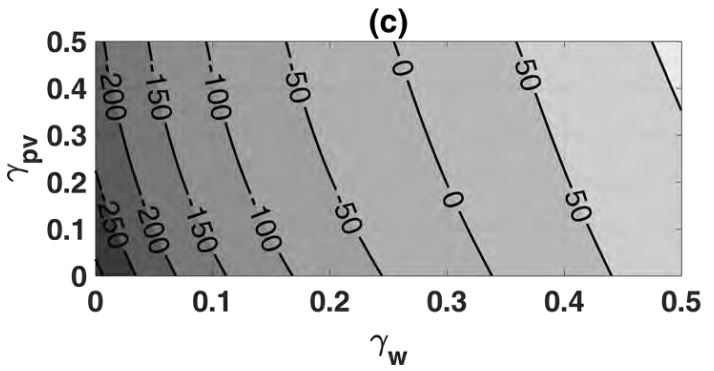

(b)

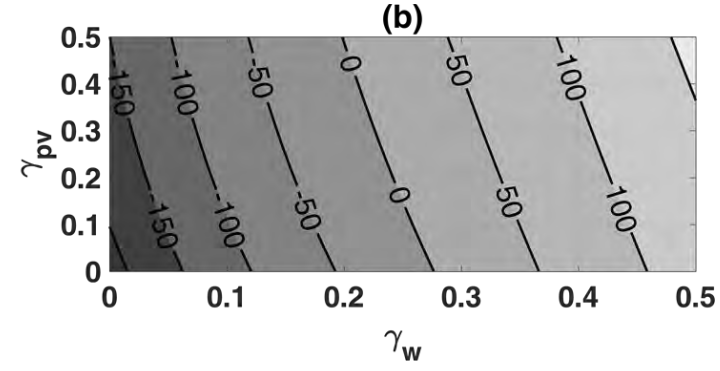

(d)

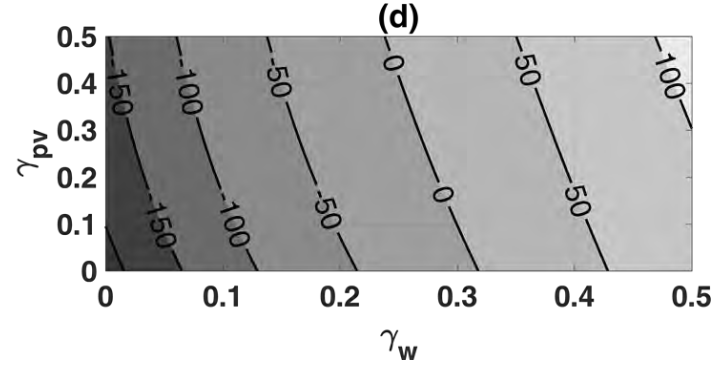

518

519

520

521

522

523

524

525

526

527

528

529

530

531

Figure 6. Case with the CHP which is powered by PtG-produced fuels (a) $\Phi$ for $\mathrm{H}_{2}$ and GT for the electric storage; (b) $\Phi$ for $\mathrm{H}_{2}$ and CCGT for the electric storage; (c) $\Phi$ for $\mathrm{CH}_{4}$ and $\mathrm{GT}$ for the electric storage; (d) $\Phi$ for $\mathrm{CH}_{4}$ and CCGT for the electric storage.

Again, the situation with the lowest energy penalty corresponds to the storage as hydrogen and the use of combined cycles in the electricity generation, while the most penalized combination comes from the storage of methane and its conversion into electricity in gas turbine cycles. Prospective studies point out that these values of photovoltaic installed capacity could be reached in the country [12] while required wind installed capacities are far beyond the figures estimated in these studies [11].

\subsection{Scenario 3: Back-up and CHP coverage with FC technologies.}

Scenario 3 introduces the possible modification of electricity generation technology to a more efficient one such as high temperature fuel cells. This technology will be applied to (i) only backup technology and (ii) both back-up and CHP technology. Therefore, given the technology 
considered in this scenario, only hydrogen is accounted as possible synthetic gaseous fuel generated by PtG.

534 The high temperature fuel cells used in CHP characterized by an electric efficiency equal to 0.6 535 and a thermal efficiency equal to 0.2. Since these efficiencies are different from the current ones, 536 being equal the produced thermal energy, the CHP electric production must be re-scaled. CHP 537 electric production pattern is considered to remain unchanged, but the size of the power produced 538 in each hour is calculated using equation (Eq. 9). The new electric efficiency of CHP technology 539 modifies the production data, thus, for the same values of $\gamma_{w}$ and $\gamma_{p v}$, a PtG capacity different from 540 Scenarios 1 and 2 is expected. Apart from this, the workflow of this case is the same.

541 In Figure 7, results related with the PtG capacity, the amount of energy stored as $\mathrm{H}_{2}$, the values 542 assumed by $\Phi$ with or without considering the quota of fuel needed to power the CHP are reported.

(a)

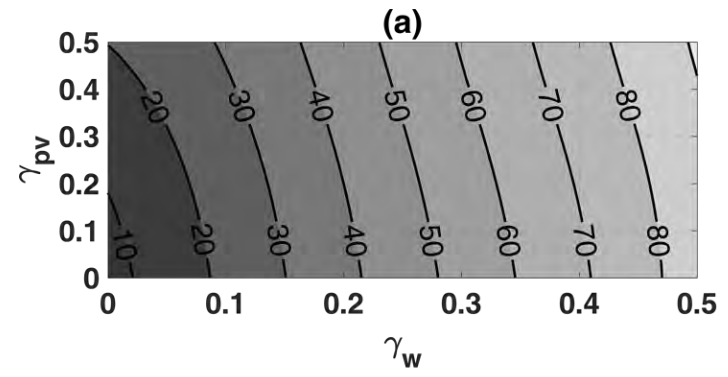

(c)

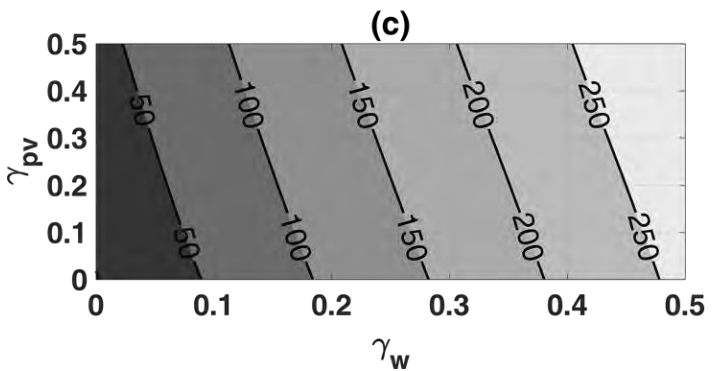

(b)

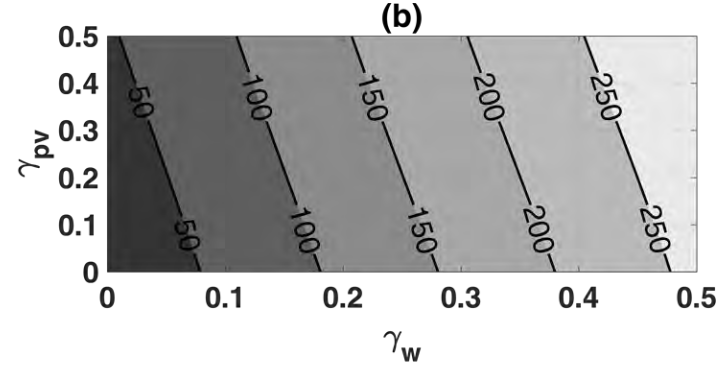

(d)

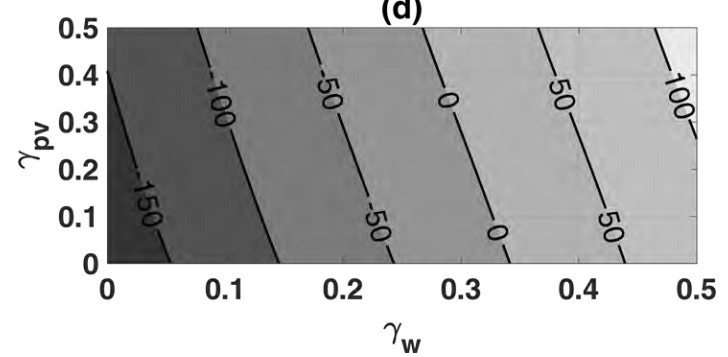

543

544

545

546

547

548

549

550

551

552

553

554

555

Figure 7. (a) PtG capacity [GW]; (b) Energy stored as $\mathrm{H}_{2}$ [TWh]; (c) $\Phi$ for $\mathrm{H}_{2}$ and FC, without considering the CHP energy requirements; (d) $\Phi$ for $\mathrm{H}_{2}$ and $F C$ considering the CHP energy requirements.

PtG installed capacities obtained in Scenario 3 vary from 6.9 GW for current installed capacities of wind and photovoltaic power to $91.4 \mathrm{GW}$ to the highest non-dispatchable installed capacities considered in the calculations, $(0.5,0.5)$. When comparing Figure 7 (a) and 4 (a), it is clear that the effects of the increased CHP electric production strongly influences the optimal PtG installed capacity for low values of $\gamma_{w}$ and $\gamma_{p v}$. Higher wind and photovoltaic installed capacities overshadow the CHP production.

Figure 7 (b) indicates that the annual chemical energy stored in the form of hydrogen could vary between 13.5 and 298.3 TWh which represent up to $20.7 \%$ of the annual primary energy consumption in the country. Furthermore, comparing Figure 7 (b) and 7 (c) it becomes clear that the system does not need any electric storage service to decarbonize the participation of back-up 
technologies. In fact, the stored energy and $\Phi$ are equal what means that there is no residual load to be covered by back-up technologies even for current RES installed capacities; i.e. the increased CHP production is enough to cover the electric demand also for low values of $\gamma_{w}$ and $\gamma_{p v}$. In Scenario 3, the whole amount of fuel produced from PtG is used to power the CHP facilities. To totally cover the CHP demand without hydrogen supplied from abroad, the quota of installed RES must be pretty high, as showed in Figure 7 (d). RES combinations that fulfil the condition established in Scenario 3 ranges between (i) $4.4 \mathrm{GW}$ of photovoltaic power and $114.6 \mathrm{GW}$ of wind power and (ii) $35.45 \mathrm{GW}$ photovoltaic power and $93.0 \mathrm{GW}$ of wind power.

\subsection{Potential denuclearization of the energy mix under SC1, SC2 and SC3}

This section summarizes the results obtained when the previously described scenarios introduce a modification in the electricity production data: not considering the contribution of the nuclear plants. The trends illustrated in Figure 8 are similar to those reported in Figure 4, but the values are systematically decreased because the duration curve is lowered by the absence of nuclear production. Installed PtG capacity estimated to better manage surplus situations varies up to 76.2 GW for the highest RES penetration analyzed in the study while for non-denuclearized $S C 1$ and $571 S C 2$ was calculated in $82.4 \mathrm{GW}$.

(a)

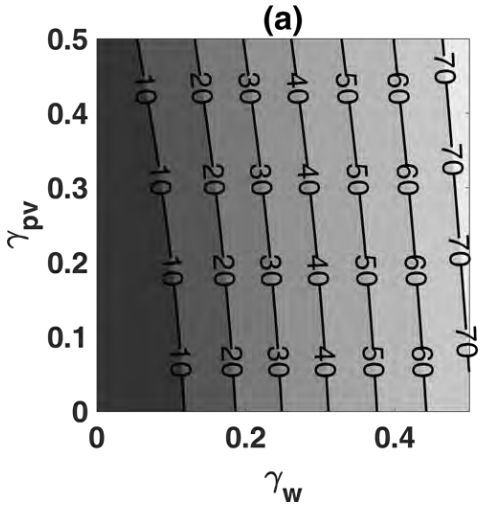

(b)

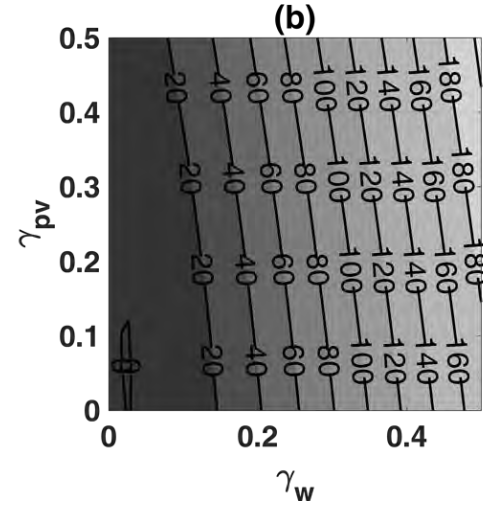

(c)

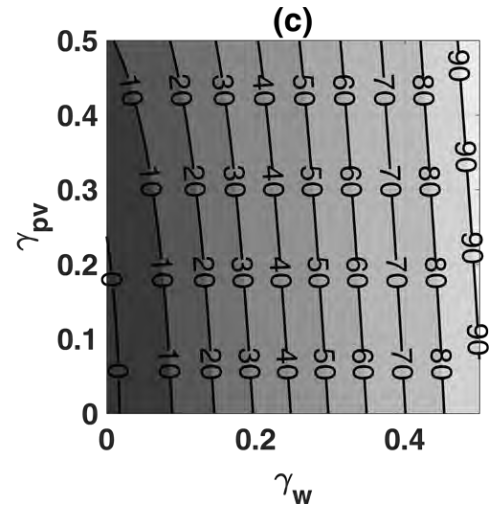

572

573

574

575

576

577

578

579

580

581

582

Figure 8. (a) PtG capacity [GW]; (b) Energy stored as H2 [TWh]; (c) Energy dumped [TWh].

Under the denuclearized scenario, the annual amount of energy stored as hydrogen calculated through (Eq. 5) ranges from $0 \mathrm{TWh}$ to $204.6 \mathrm{TWh}$ which corresponds to approximately a 14\% of the total primary energy consumed in the country. The amount of surplus energy which cannot be handled by the installed PtG capacity along the year is $96.4 \mathrm{TWh}$. This amount should be stored by means of a different storage technology.

Analogous consideration can be deduced from Figure 5 and Figure 9. The trends are similar but the values of $\gamma_{w}$ and $\gamma_{p v}$ which make $\Phi$ equal to zero are much higher than those reported for SC1. Therefore, while retaining the current fossil-fueled CHP facilities, it would be possible to cover 
583 the annual electrical demand after removing the nuclear energy from the Spanish energy mix, by

584 installing additional wind and photovoltaic power and applying PtG as electric storage. The share

585 of installed RES which fulfil this condition is rather high and its economic feasibility should be

586 analyzed. If methane is accounted as energy vector, the installed capacities of wind which fulfil

587 the SCl conditions ranges between 76.4 and $130.1 \mathrm{GW}$, for 66.5 and $4.4 \mathrm{GW}$ of photovoltaic 588 power, respectively.

(a)

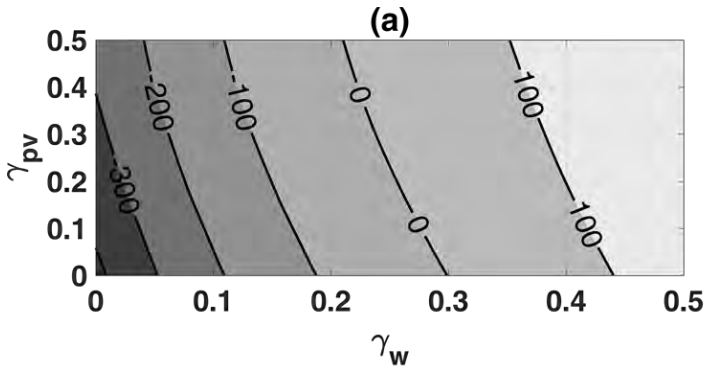

(c)

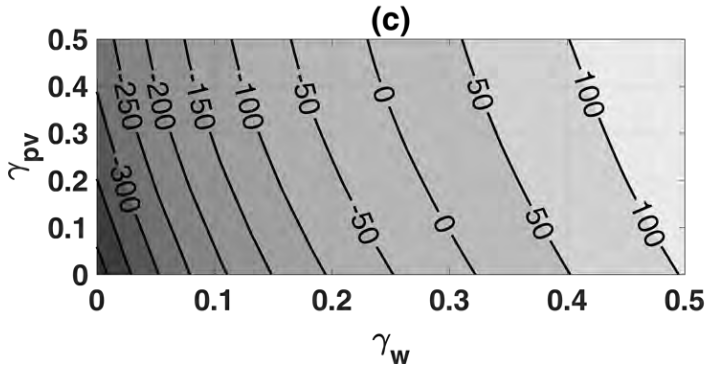

(b)

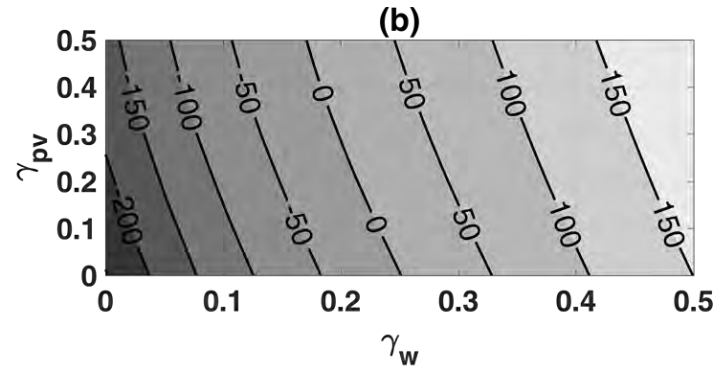

(d)

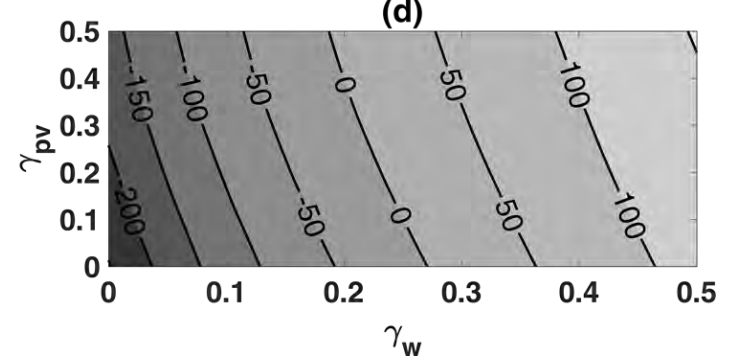

589

590

591

592

593

594

595

596

597

598

599

Figure 9. (a) $\Phi$ for H2 and GT; (b) $\Phi$ for H2 and CCGT; (c) $\Phi$ for CH4 and GT; (d) $\Phi$ for CH4 and CCGT.

Figure 10 reports the results of denuclearized Scenario 2 in which the CHP is powered by the fuel produced by the PtG. Again it would be still possible to fulfil the energy requirements of the electric system with the adequate combination of wind, photovoltaic and PtG installed capacities. Though, the RES capacity required is extremely high. In fact, for $\gamma_{w}$ equal to 0.35 and $\gamma_{p v}$ equal to 0.25 (one of the cases which satisfy the condition $\Phi=0$ for $\mathrm{H}_{2}$ as stored fuel and CCGT as electricity conversion technology) the installed capacity of photovoltaic and wind is approximately equal to $154 \mathrm{GW}$, against a demand peak in the 2016 of around $40 \mathrm{GW}$. It is therefore clear that the system would need to be greatly oversized when the electricity production is entrusted only to RES. 
(a)

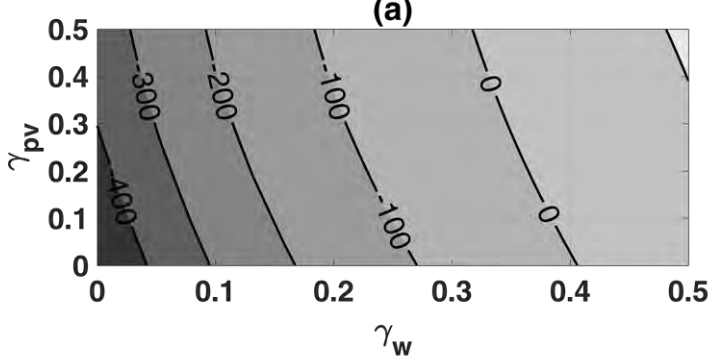

(c)

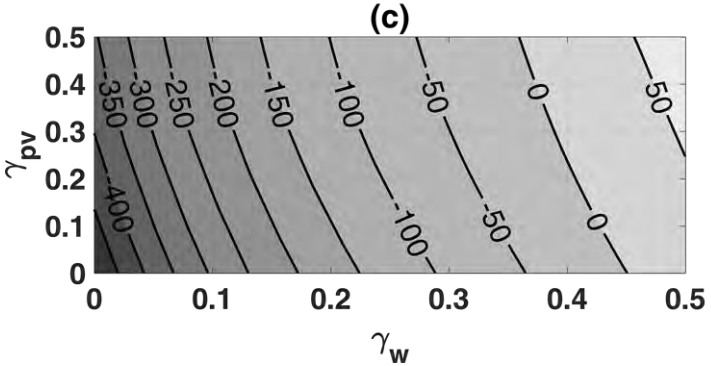

(b)

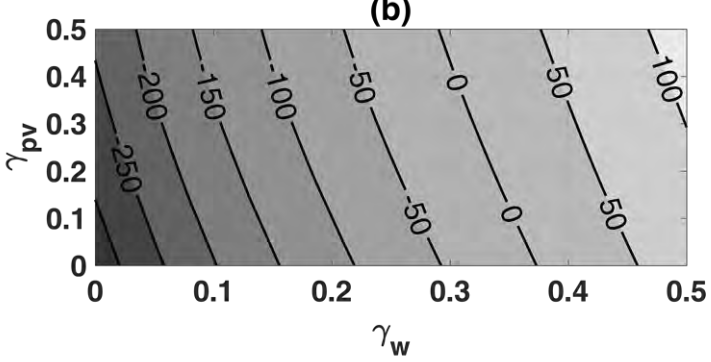

(d)

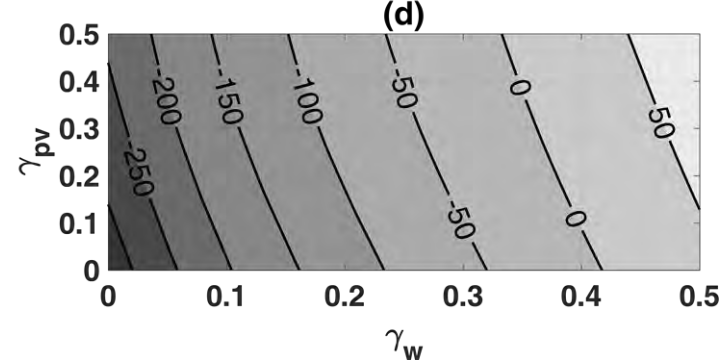

601

604

605

606

607

608

Figure 10. (a) $\Phi$ for H2 and GT for the electric storage; (b) $\Phi$ for H2 and CCGT for the electric storage; (c) $\Phi$ for CH4 and GT for the electric storage; (d) $\Phi$ for CH4 and CCGT for the electric storage. Case with the CHP which is powered by PtG-produced fuels.

Lastly, the results for a denuclearized Scenario 3 are reported in Figure 11. Under SC3, the energy was only stored as hydrogen later converted into electric energy by means of fuel cells to cover both types of demands: back-up technologies and CHP production. The PtG installed capacity obtained following the proposed methodology is $84.6 \mathrm{GW}(7 \mathrm{GW}$ lower than the option which include nuclear production).

(a)

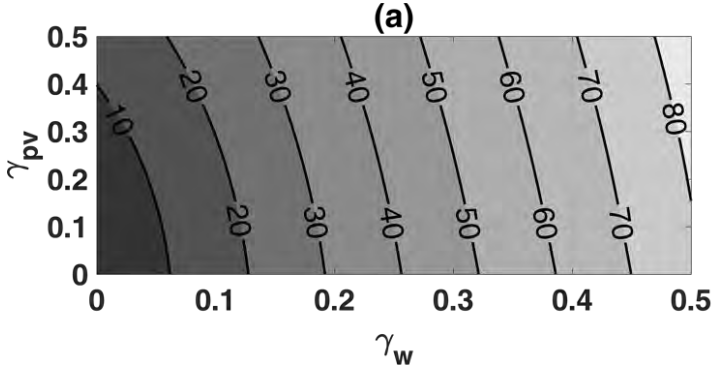

(c)

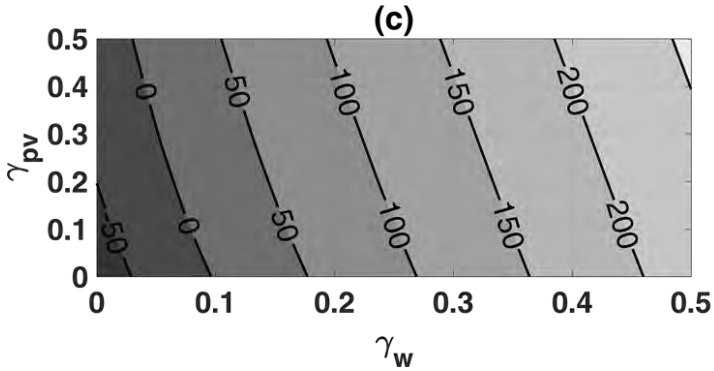

(b)

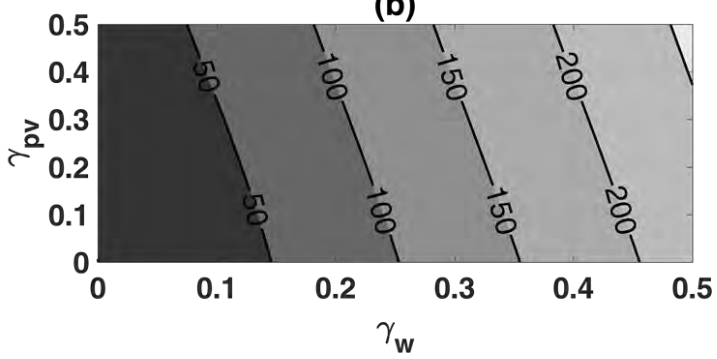

(d)

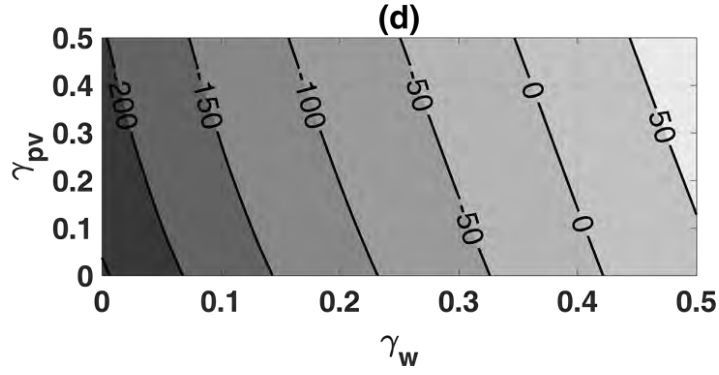

609

610

611

612

613

614

Figure 11. (a) PtG capacity [GW]; (b) Energy stored as H2 [TWh]; (c) $\Phi$ for H2 and FC for the electric storage, without considering the CHP energy requirements; (d) $\Phi$ for $\mathrm{H} 2$ and FC for the electric storage, considering the CHP energy requirements.

The main difference with the case that includes nuclear production (SC3) relies in the increase of CHP electric production. Given the modification of the ratio between the electric and thermal 
615 efficiency in CHP systems, the annual stored energy and $\Phi$ (calculated without considering the

616 CHP energy requirements) are not equal anymore. This behavior corresponds to negative values

617 of $B E_{t}$ (requirement of back-up technology) during the year.

618 In analogy with the previous cases, when fuel required by the CHP is considered into the $\Phi$

619 calculation (Figure 11 (d)), the values of $\gamma_{w}$ and $\gamma_{p v}$ required to cover the electric demand of the 620 system by means of RES and PtG installed capacities, are pretty high. The increase in CHP 621 production affects the duration curve shape, thus, this case is not the most burdensome from the 622 load coverage point of view.

623 A detailed economic analysis to assess the levelized cost of electricity of variable renewable [39] 624 under each of the proposed scenarios will complete the information required to understand which 625 scenario is more reliable to be implemented in order to manage high wind and photovoltaic energy 626 penetration in the Spanish electrical system. However, a thorough economic analysis of the 627 proposed scenarios is beyond the scope of the study whose objective is the assessment of the 628 technical feasibility.

629 5. Conclusions.

630 This study estimates the required installed power of wind, photovoltaic and PtG in Spain to 631 decarbonize the electric system in the mid-large term. The analysis uses the maximum technical 632 potential of installing new wind and PV power capacity as a measure of the feasibility of results.

633 The used methodology combines the definition of the balance of energy at time $t, B E_{t}$, which 634 shows the surplus energy situations (positive values) as well as the back-up requirements 635 (negative values) every hour. This allows to properly size the PtG capacity by maximizing the 636 amount of stored electricity at nominal load in the duration curve. Then, the whole system is 637 solved by iterative calculations that make match the negative values of $B E_{t}$, with the recoverable 638 electricity from the stored synthetic fuels, by modifying the installed capacity of wind and PV in 639 each iteration.

640 Three scenarios are defined to reach different levels of decarbonization in the electricity system:

641 (i) decarbonize only back-up technologies in electric generation, (ii) to additionally decarbonize 642 industrial CHP in the country without replacing current CHP technologies and (iii) to decarbonize 643 both back-up and CHP by considering fuel cells supplied with renewable $\mathrm{H}_{2}$ as implemented 644 technology. All these scenarios may be covered by installing RES capacities below the technical 645 potential estimated for the country. Installed PtG capacities between 80 and $90 \mathrm{GW}$ will be 646 required depending on the expected conditions of electrical coverage. This system allows to store 647 an amount of surplus energy which is equivalent to $17 \%$ of total primary energy consumption in 648 the country. 
649 Finally, a potential denuclearization is approached. The same scenarios are studied without

650 accounting for nuclear power in the electrical generation system. The technical potential of wind

651 and photovoltaic power capacity to fulfil this condition is not surpassed but the required capacities

652 are extremely high and the economic feasibility of such system should be further analyzed.

\section{Nomenclature}

$C_{i} \quad$ Installed capacity of technology $i$

[GW]

$E_{i, t} \quad$ Electricity generated by technology $i$ at hour $t$

$D_{t} \quad$ Electrical demand at hour $t$

$h_{\text {nom }} \quad$ Number of hours working at nominal load

[h]

$S E_{t} \quad$ Surplus energy at hour $t$

$\eta_{H 2} \quad$ Efficiency of electrolyzer

$\eta_{\mathrm{CH} 4} \quad$ Efficiency of methanation process

$\eta_{G T} \quad$ Thermal efficiency of gas turbine cycle

$[-]$

$\eta_{C C G T} \quad$ Thermal efficiency of combined cycle

$[-]$

$\eta_{F C} \quad$ Efficiency of fuel cell system

$[-]$

$\gamma_{w} \quad$ Percentage of increased installed capacity of wind power

$[-]$

$\gamma_{p v} \quad$ Percentage of increased installed capacity of PV power

$\Phi$

Difference between stored energy and required stored energy

\section{Subscripts}

$\begin{array}{ll}P t G & \text { Power to Gas } \\ P V & \text { Photovoltaic power } \\ s t & \text { stored } \\ w & \text { Wind power }\end{array}$

656

\section{Acronyms}

BL

CAES

$\mathrm{CC}$

CHP

ECS

FC

FES

GT

HES

ND

PHS

PtG
Base load

Compressed air energy storage

Combined cycle

Combined heat and power

Electrochemical storage

Fuel cell

Flywheels energy storage

Gas turbine

Hydrogen energy storage

Non-dispatchable

Pumped hydroelectric storage

Power-to-Gas 
RED

RES

TES
Renewable energy directive

Renewable energy sources

Thermal energy storage
659

660

661

662

663

664

665

666

667

668

669

670

671

672

673

674

675

676

677

678

679

680

681

682

683

684

685

686

687

688

689

690

691

692

693

694

695

696

\section{Acknowledgments}

Financial support for M.B. during his Ph.D. studies was co-funded by the Department of Industry and Innovation of Diputación General de Aragón, and by the European Social Fund. The authors would also like to acknowledge funding from Ministerio de Educación, Cultura y Deporte through the program "José Castillejo", CAS16/00065.

\section{References}

[1] European Parliament. Directive 2009/28/EC of the European Parliament and of the Council of 23 April 2009. Off J Eur Union 2009;140:16-62. doi:10.3000/17252555.L_2009.140.eng.

[2] European Commission. Proposal for a directive of the European Parliament and of the council on the promotion of the use of energy from renewable sources (recast) 2017;0382 (COD):1-116.

[3] International Energy Agency IEA. Energy Policies of IEA Countries: Spain 2015 Review. 2015.

[4] European Commission. Renewable energy progress report. Rep From Comm To Eur Parliam Counc Eur Econ Soc Comm Comm Reg 2015;293:16. doi:10.1017/CBO9781107415324.004.

[5] Schlachtberger DP, Brown T, Schramm S, Greiner M. The benefits of cooperation in a highly renewable European electricity network. Energy 2017;134:469-81. doi:10.1016/j.energy.2017.06.004.

[6] Aneke M, Wang M. Energy storage technologies and real life applications - A state of the art review. Appl Energy 2016;179:350-77. doi:10.1016/j.apenergy.2016.06.097.

[7] Kirkerud JG, Bolkesjø TF, Trømborg E. Power-to-heat as a flexibility measure for integration of renewable energy. Energy 2017;128:776-84. doi:10.1016/j.energy.2017.03.153.

[8] Kheradmand-Khanekehdani H, Gitizadeh M. Well-being analysis of distribution network in the presence of electric vehicles. Energy 2018;155:610-9. doi:10.1016/j.energy.2018.04.164.

[9] Götz M, Lefebvre J, Mörs F, McDaniel Koch A, Graf F, Bajohr S, et al. Renewable Power-to-Gas: A technological and economic review. Renew Energy 2016;85:1371-90. doi:10.1016/j.renene.2015.07.066.

[10] Connolly D. Heat Roadmap Europe: Quantitative comparison between the electricity, heating, and cooling sectors for different European countries. Energy 2017;139:580-93. doi:10.1016/j.energy.2017.07.037.

[11] EWEA. Wind energy scenarios for 2030. Ewea 2015:1-8.

[12] Hoefnagels R, Junginger M, Panzer C, Resch G, Held A. Long Term Potentials and Costs of RES Part I: Potentials, Diffusion and Technological learning. RE-Shaping D10 Report 2011:99. 
[13] IDAE. Informe de sostenibilidad ambiental del Plan de Energías Renovables 2011-2020. 2011.

[14] Aymami, J; García, A; Lacave, O; Lledó, L; Mayo, M; Parés S. Análisis del recurso. Estudio técnico PER 2011-2020.Atlas eólico de España 2011.

[15] International Energy Agency IEA. Potential for building integrated photovoltaics. IEAPVPS Task 2002;2002:2-4.

[16] MAPAMA. Factores de emisión: registro de huella de carbono, compensación y proyectos de absorción de dióxido de carbono. 2017.

[17] Red Eléctrica Española. ESIOS-REE Transparency Report. 2017.

[18] MINETUR. Planificación energética indicativa según lo dispuesto en la Ley 2 / 2011 , de 4 de marzo, de Economía Sostenible. 2011.

[19] Club Español De La Energia. Balance Energético de 2016 y Perspectivas para 2017. 2016.

[20] Qadrdan M, Abeysekera M, Chaudry M, Wu J JN. Role of power-to-gas in an integrated gas and electricity system in Great Britain. Int J Hydrog Energy 2015;40:63-75. doi:doi:10.1016/j.ijhydene.2015.03.004.

[21] Bailera M, Lisbona P. Energy storage in Spain: forecasting electricity excess and assessment of Power-to-Gas potential up to 2050. Energy 2017. doi:10.1016/j.energy.2017.11.069.

[22] Varone A FM. Power to liquid and power to gas: An option for the German Energiewende. Renew Sustain Energy Rev 2015;45:207-18. doi:doi:10.1016/j.rser.2015.01.049.

[23] Dominković DF, Dobravec V, Jiang Y, Nielsen PS, Krajačić G. Modelling smart energy systems in tropical regions. Energy 2018;155:592-609. doi:10.1016/j.energy.2018.05.007.

[24] International Energy Agency IEA. Energy Technology Perspectives 2017. IEA; 2017. doi:10.1787/energy_tech-2017-en.

[25] Guandalini G, Robinius M, Grube T, Campanari S, Stolten D. Long-term power-to-gas potential from wind and solar power: A country analysis for Italy. Int J Hydrogen Energy 2017:1-18. doi:10.1016/j.ijhydene.2017.03.081.

[26] Colbertaldo P, Guandalini G, Campanari S. Modelling the integrated power and transport energy system: The role of power-to-gas and hydrogen in long-term scenarios for Italy. Energy 2018;154:592-601. doi:10.1016/j.energy.2018.04.089.

[27] Red Eléctrica Española. The Spanish Electricity System - Preliminary report 2017. 2018.

[28] European Environment Agency. Overview of electricity production and use in Europe. 2015.

[29] UNESA. Prospectiva de generación eléctrica 2030. 2007.

[30] Ministerio de Industria Energía y Turismo. Orden IET/2101/2014, de 3 de noviembre, por la que se concede la renovación de la autorización de explotación de la central nuclear Trillo I. 2014.

[31] Lechtenböhmer S, Nilsson LJ, Åhman M, Schneider C. Decarbonising the energy intensive basic materials industry through electrification - Implications for future EU electricity demand. Energy 2016;115:1623-31. doi:10.1016/j.energy.2016.07.110. 
[32] Bailera M, Lisbona P. Energy storage in Spain: Forecasting electricity excess and assessment of power-to-gas potential up to 2050. Energy 2018;143. doi:10.1016/j.energy.2017.11.069.

[33] Montoya FG, Aguilera MJ, Manzano-Agugliaro F. Renewable energy production in Spain: A review. Renew Sustain Energy Rev 2014;33:509-31. doi:10.1016/j.rser.2014.01.091.

[34] International Energy Agency IEA. Technology Roadmap Solar Thermal Electricity. 2014. doi:10.1007/SpringerReference_7300.

[35] Koponen J. Review of water electrolysis technologies and design of renewable hydrogen production systems. Lappeenranta University of Technology, 2015.

[36] Miguel C V., Soria MA, Mendes A, Madeira LM. A sorptive reactor for CO2capture and conversion to renewable methane. Chem Eng J 2017;322:590-602. doi:10.1016/j.cej.2017.04.024.

[37] Ghaib K, Ben-Fares FZ. Power-to-Methane: A state-of-the-art review. Renew Sustain Energy Rev 2018;81:433-46. doi:10.1016/j.rser.2017.08.004.

[38] MINETUR. La Energía en España 2016. 2017.

[39] Reichenberg L, Hedenus F, Odenberger M, Johnsson F. The marginal system LCOE of variable renewables - Evaluating high penetration levels of wind and solar in Europe. Energy 2018;152:914-24. doi:10.1016/j.energy.2018.02.061. 